John Carroll University

Carroll Collected

Economics \& Finance

1977

\title{
Socioeconomic Determinants of Migration and Level of Aggregation
}

FrankJ. Navratil

John Carroll University, navratil@jcu.edu

James J. Doyle

Follow this and additional works at: http://collected.jcu.edu/econ_fin-facpub

Part of the Economics Commons, and the Finance and Financial Management Commons

\section{Recommended Citation}

Navratil, Frank J. and Doyle, James J., "Socioeconomic Determinants of Migration and Level of Aggregation" (1977). Economics \& Finance. 4.

http://collected.jcu.edu/econ_fin-facpub/4 


\title{
THE SOCIOECONOMIC DETERMINANTS OF MIGRATION AND THE LEVEL OF AGGREGATION*
}

\author{
FRANK J NAVRATIL \\ John Carroll L'meersu \\ JAMES J. DOYLE \\ John Carroll Lneersity
}

\section{INTRODUCTION}

The decision to migrate may be considered a two-dimensional process. The first dimension involves the decision of whether or not to relocate, while the second dimension (or phase) concerns the question of exactly where to relocate.' The personal characteristics of a migrant, particularly age and education, tend to significantly influence the first phase of the migration decision. The second phase, on the other hand, tends to be a function of the labor market characteristics of an area which makes it attractive to migrants, such as higher relative (to the origin area) wage rates, lower unemployment rates, and so forth. Hence, a complete model of the migration decision should encompass both the personal characteristics of migrants and the labor market characteristics of the destination area.

However, an extensive investigation of the literature in the area of human migration reveals that no one has yet attempted to incorporate both personal and area characteristics into a single model. For example,

* The authors wish to thank Stanley H. Masters, Monroe $O$ Newman. Sonia $S$ Gold, Michael J Lavelle, $\mathrm{S} J$., and an anonymous referee for their comments on an earher version of this article The authors also wish to acknowledge the cooperation and financial support of John Carroll University An earlier version of this paper was presented at the Southern Regional Science Assoc:ation Convention in Richmond, Virgınıa, April 8-10. 1976

1 Of course, these dimensıons are often inseparable A decision to relocate is most often made simultaneously with the decision to relocate to a specific area
Ladinsky [10], Kaluzny [8], and Bowles [1] focused on the personal characteristics of migrants, and thus ignored the impact of area characteristics. Other researchers, such as Greenwood [6, 7], Gallaway, Gilbert, and Smith [4], Rogers [14], and Wadycki [18], to name just a few, measured the effects of area characteristics. Most likely, the data used in their studies did not permit them to analyze the role that personal characteristics play in the propensity to migrate. Accordingly, previous research in this area is subject to serious specification bias by ignoring one of the two dimensions of the decision to migrate.

An extensive exploration of the literature also reveals a paucity of studies which focus explicitly on the determinants of an individual's decision to migrate. Most of the research has concentrated on the factors which influence aggregate measures of the propensity to migrate. For example, typical dependent variables include the gross or net rate of inmigration or the gross or net rate of outmigration by specific cohort groups. The one study which has focused on the individual per se (that of Kaluzny) did not incorporate a full range of socioeconomic variables and did not include the labor market characteristics of destination areas which are prevalent in the aggregate studies.

Further, no one has yet investigated the extent to which extrapolation of the conclusions based on aggregate measures to the individual decision maker is a legitimate procedure in migration research. The process of aggregation may mask some of the factors 
important to the individual's decision, while at the same time it may exaggerate others.

Accordingly, the purpose of this paper is threefold. First, it is an attempt to combine personal and area characteristics which influence the propensity to migrate and thereby overcome the specification bias present in previous studies. Second, it is an attempt to fill the present void in the literature by focusing on the socioeconomic determinants of an individual's propensity to migrate. Third, it is an attempt to explore the sensitivity of these determinants to different levels of aggregation.

To accomplish this, two models are constructed and tested empirically. The first is an aggregate model which considers the rates of inmigration by sex and race to be a function of the "average" socioeconomic characteristics of individuals in that group and of the labor market characteristics of the areas to which these groups were attracted. The second model is a disaggregated version of the first model. It treats an individual's decision to migrate as a function of the socioeconomic characteristics of that individual and also the labor market conditions of his destination area. Since the decision to migrate is an "all or nothing" phenomenon, probit analysis is the statistical technique employed in the second model. This technique permits the identification of those factors which affect the probability of "success," which in this case is to be equated with the decision to migrate.

\section{THE THEORETICAL MODEL}

The modern economic treatment of the migration decision treats migration as an investment in human capital [1]. According to this approach, a utility-maximizer would invest (i.e., decide to migrate) whenever the benefits of migration exceed the costs, after properly discounting both to their present values and then summing.

Within this framework, a number of area characteristics are likely to exert an important influence on the propensity to migrate.
Research conducted by Greenwood [7], Raimon [13], and Lowry [11] using aggregate data has revealed that migration into an area is positively affected by an area's rate of employment growth, degree of urbanization, temperature, educational level, per capita income, and the number of persons who migrated to the area in past periods, and negatively affected by the distance separating the origin and the destination areas, and by the unemployment rate of the destination area.

The propensity to migrate is also likely to be influenced by the size of the destination area. It may be an important factor because larger population centers offer a greater variety of occupational choice, cultural and social amenities, etc., than smaller centers. On the other hand, size may actually exert a negative influence on migration due to the disutility associated with greater degrees of noise, congestion, pollution, and crime.

The decision to migrate is also dependent upon a number of the personal characteristics of a migrant. Gallaway [3] and Wertheimer [20] have demonstrated that mobility declines with age, while Suval and Hamilton [16] have disclosed that it increases with education.

Other personal characteristics which may be significant in influencing migration are employment status, life style, military status, and previous migration by the individual. ${ }^{2}$ The probability that a labor force member will migrate is likely to increase when an individual is unemployed, ceteris paribus, since the unemployed are likely to perceive greater expected returns to mobility than the employed. Moreover, the unemployed are

\footnotetext{
${ }^{2}$ Research conducted by Gallaway, Gilbert, and Smith [4] and Greenwood [7] suggests that low income persons are more likely to respond to a given income differential than high income persons; hence, we expect low income individuals to be more mobile than high income persons. Unfortunately, the only income data which was avalable was for the year 1969. Income in that year could be as much a result of migration in the 1965-1970 period as it could be a cause of migration. Because of the ambiguity in interpreting this variable and also because it was highly collinear with both age and education, it was dropped from the set of causal factors.
} 
less likely to have an incentive to remain in a given area as compared to their employed counterparts. It is also reasonable to expect that established families would be less mobile because of the added costs of moving an entire family, which for most implies the additional cost of selling their present home and purchasing another in the destination area. Individuals who were in the military prior to joining the civilian labor force are also likely to be more mobile than others, since military personnel are often relocated on short notice for national defense purposes. Finally, persons who have moved at least once in the past are more likely to move again than persons who have not yet experienced their first move. Using data for the 1968-1970 period, Kaluzny found that previous migration exerted a strong direct effect on the probability of present migration.

\section{THE DATA}

The major source of data used in this study was the 5\% county group Public Use Sample Tapes of the Basic Records of the 1970 Census [21]. It provided information by individual records on age, sex, race, education, income, state of birth, marital status, employment status in 1965, military status, and state of residence in 1965. A county group is considered to be a labor market area by the Bureau of the Census.

The data were processed to produce a classification by migratory status based on state of residence in 1965 as compared to 1970. Since several labor market areas overlap two or more states, it is possible that an individual could change states without leaving a particular labor market area. In order to insure that when an individual changed states he necessarily changed labor market areas, only the 82 labor markets contained entirely within a state were chosen for purposes of this study. They represent more than half of all the counties in the United States and include some parts of all states except Vermont, Delaware, North and South Dakota, Montana, Wyoming, and Idaho. A migrant is thus defined as an individual of working age (16-75) in 1970 who resided in a different labor market area in 1970 from the one in which he resided in 1965.

One problem typically found in Census Bureau data (especially the aggregate data) is that all persons, regardless of age and employment status, are given equal weights, and this tends to blur the results. While migration because of potential or actual employment should be related to a number of different economic determinants, migration for purposes of higher education may not. High rates of inmigration to such locales as Palo Alto, California, or State College, Pennsylvania may be the result of educationally related inmigration rather than because of employment opportunities. Outmigration from such areas would, however, tend to be employment related, as graduates seek jobs.

In order to overcome such problems our study used only those individuals who were classified as chief income recipients by the Census and who were in the civilian labor force in 1970. Thus, children, spouses and those individuals who were in the military in 1970 or who were retired are excluded from the analysis. ${ }^{3}$ There were approximately 220,000 such individuals who resided in the 82 labor market areas considered in this study. For the disaggregate portion of this study a one-in-twenty random sample of whites and a one-in-four random sample of blacks were used.

\section{THE EMPIRICAL MODELS}

The basic model to be tested in this paper takes the form:

$$
M_{i j}=f\left[P C_{\imath}, L M_{j}, G_{\jmath}, u_{1 \jmath}\right]
$$

Where

$M_{11}=$ migratory status during the 1965-70 period.

\footnotetext{
${ }^{3}$ We are implicitly assumıng that migration decisions are based on the employment prospects of the chief income recipients and not those of any secondary income recıpients.
} 
$P C_{1}=$ the personal characteristics of individual $i$.

$L M_{3}=$ the labor market characteristics of area $j$.

$G_{j}=$ the geographical characteristics of area $j$.

$u_{1,}=$ a stochastic error term.

Operationally the following variables were used in the aggregate portion of the study:

$M_{l j}=$ gross number of inmigrants into area $j$ by a specific race-sex cohort group $i$ over the 1965-70 period relative to the total population in group $i$ in area $j$ in 1970.

The personal characteristics of individuals are captured through the use of the following variables:

$\%$ MAR = percentage of a specific migrant cohort group who were married in 1970 (serves as a proxy for life style).

\% UNG $=$ percentage of a specific migrant cohort group who were unemployed in 1965.

$\% \mathrm{MIL}=$ percentage of a specific migrant cohort group who were in the military in 1965.

AGE = average 1970 age of a specific migrant cohort group $i$.

EDUC = average number of years of school completed in 1970 by a specific migrant cohort group $i$.

The labor market characteristics used include:

$\% \mathrm{UN}=$ percentage of the labor force of area $j$ who were unemployed in 1965.

GRW = rate of growth of employment in area $j$ over 1965-70 period.

URB = percentage of the total population of area $j$ living in urban areas in 1970.

AVED $=$ average 1970 education of the 1965 labor force in area $j$.

PCY $=$ per capita income in 1966 in area $j$. MSR $=$ number of persons who resided in area $j$ in 1965 who were born in another state divided by the 1970 population of area $j{ }^{4}$

POP $=$ number of persons residing in area $j$ in 1970.

Geographical characteristics include:

TEMP = average annual temperature of the major urban center in area $j$.

DIST = modal distance traveled by inmigrants into area $j$ in thousands of standard highway miles (measured by distance between a capital city of an origin state and the major urban center of area $j$ ).

The disaggregate model may be expressed in a similar fashion:

$$
D_{\imath \jmath}=f\left[P C_{\imath}, L M_{\jmath}, G_{\jmath}, u_{\imath \jmath}\right]
$$

Where

$D_{\imath \jmath}=$ a dichotomous variable equal to 1 if individual $i$ migrated to area $i$ over the 1965-70 period; 0 otherwise.

Personal characteristics include:

DMAR $=$ a dichotomous variable equal to 1 if individual $i$ was married in 1970; 0 otherwise.

UN5YA $=$ a dichotomous variable equal to 1 if individual $i$ was unemployed in 1965; 0 otherwise.

DM5YA = a dichotomous variable equal to 1 if an individual was in the armed forces in 1965; 0 otherwise.

PREVM = a dichotomous variable equal to 1 if individual $i$ lived in a different area in 1965 than the one in which he was born; 0 otherwise.

AGE $=1970$ age of individual $i$.

EDUC = number of years of school completed by individual $i$ in 1970 .

The area labor market characteristics and

4 The migrant stock rate (MSR) as defined above was used rather than a simple migrant stock variable because: 1) migrant stock is highly collinear with population; and 2) MSR itself is a surrogate for previous migration, a variable used in the disaggregate model. 
geographical characteristics are the same as in the aggregate model.

The two models are basically the same, although the disaggregate deals with the individual whereas the aggregate uses average values for those persons who migrated within a specific demographic group. There is one variable which is used in the disaggregate model for which there is no counterpart in the aggregate form. PREVM attempts to measure the impact of past migration on current migration. For the aggregate model PREVM would tend to be highly collinear with the migrant stock rate variable, if it was defined as the percentage of individuals who resided in a different area in 1965 than the one in which they were born. Thus, it was excluded from that model.

There is also a variable in the aggregate model which has no counterpart in the disaggregate version. Distance was excluded from the disaggregate model because of the difficulty in interpreting this variable when the dependent variable is dichotomous. ${ }^{5}$

\section{RESULTS OF THE REGRESSION ANALYSIS}

Multiple regression analysis was used to estimate the aggregate model, while probit analysis was employed to estimate the disaggregate model.

Table I summarizes the results for the aggregate model. As the table reveals, age is a significant determinant for all cohort groups except white females, but has the wrong sign when it is significant. Education (EDUC) is only significant for white males, but all signs are in the direction suggested by theory. With respect to area characteristics, blacks appear to be more responsive to urbaniza-

\footnotetext{
${ }^{5}$ Recall that the dependent variable is equal to zero for continuous residents and one for migrants. If the distance were set equal to zero for contınuous residents and the actual distance otherwise, it should be apparent that there would be a strong, posuive relationship between migratory status and distance. A negative relationship between migratory status and distance could be obtained by settıng the distance variable to an extremely large value for non-migrants; however, such a technique would seem to be begging the question
}

tion, temperature, average education of the destination area, and distance than are whites. However, only whites appear to be influenced by area unemployment rates.

Table II displays the results obtained for the disaggregate model. Concerning personal characteristics, age, 1965 employment status, previous migration, and 1965 military status are statistically significant and have the hypothesized signs for all cohort groups. Education is also significant in the hypothesized direction except for black females. In terms of area characteristics, blacks again appear to be more sensitive to temperature and education, whereas whites are more attracted to areas with favorable labor market conditions (characterized by high rates of employment growth and low unemployment rates). The results concerning the effects of area income are ambiguous.

A comparison of Table I and II reveals, not surprisingly, very similar results concerning the characteristics of destination areas. The temperature variable (TEMP) proved not to be significant for the white cohorts, but it is highly significant and negative for the black cohorts in both models. ${ }^{6}$ Most likely TEMP reflects disdain on the part of non-whites to move into the South. The area education variable (AVED) also produces similar results regardless of the level of aggregation, with blacks being significantly more responsive to this characteristic than whites.

Finally, the distance variable (DIST), which only appeared in the aggregate model, proved to be insignificant for the white cohorts, but positive and significant for the

\footnotetext{
- Several other clımatic variables were used in lieu of average annual temperature, such as mean January high, mean January low, number of days between frosts, and mean July high temperature. Annual rainfall was also used. While certain of these variables improved the explanatory power of the model for one cohort group, they would reduce the explanatory power for the other cohort groups. Moreover, the incorporation of these variables had a marginal impact on the coefficients of the statistically significant variables. Consequently, we chose to retain average annual temperature as the "best" variable when all four cohort groups were considered together.
} 
TABLE I

Determinants of Migration by Sex and by

Race' Aggregate Modela

VARIABLE

WHITE MALES

WHITE FEMALES

BLACK MALES

BLACK FEMALES

COEFFICIENTS

\begin{tabular}{|c|c|c|c|c|}
\hline CONSTANT & $\begin{array}{l}-0.258 \\
(-0.90)\end{array}$ & $\begin{array}{r}-0.413 \\
(-1.26)\end{array}$ & $\begin{array}{r}-0.418 \\
(-1.30)\end{array}$ & $\begin{array}{l}-0.903^{*} \\
(-2.08)\end{array}$ \\
\hline
\end{tabular}

PERSONAL

CHARACTERISTICS

\%MAR

$-0.379^{* *}$

$(-3.54)$

$\%$ UNG

$\%$ MIL

AGE

EDUC

$$
\begin{array}{r}
-0.128 \\
(-0.95)
\end{array}
$$

0.044

$(0.34)$

$$
\begin{aligned}
& 0.011^{* *} \\
& (2.98)
\end{aligned}
$$

$-0.002$

$(-0.72)$

$$
0.018^{i * *}
$$$$
(2.42)
$$

0.009

$(0.81)$

$$
-0.050
$$

$(-1.07)$

$-0.032$

$(-0.60)$

0.011

(0.19)

$$
\begin{aligned}
& 0.003^{*} \\
& (1.68)
\end{aligned}
$$

0.004

$(0.84)$
$-0.096^{*}$

$(-1.78)$

$-0.049$

$(-1.09)$

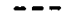

$0.003^{*}$

(1.99)

0.005

(1.28)

AREA

CHARACTERISTICS

$\begin{array}{lcccc}\text { \%UN } & -0.005^{*} & -0.010^{*} & -0.0002 & 0.002 \\ & (-1.69) & (-2.04) & (-0.03) & (0.25) \\ \text { GRW } & 0.004^{* *} & 0.005^{* *} & 0.001 & 0.003^{*} \\ & (7.01) & (6.24) & (0.92) & (1.97) \\ \text { URB } & 0.053 & 0.102 & 0.244^{* *} & 0.354^{* * *} \\ & (1.14) & (1.42) & (3.01) & (3.02) \\ \text { TEMP } & -0.0001 & 0.001 & -0.005^{* *} & -0.007^{* *} \\ & (-0.10) & (1.15) & (-4.12) & (-4.14) \\ \text { AVED } & 0.009 & 0.025 & 0.048^{*} & 0.087^{* *} \\ & (0.72) & (1.31) & (2.12) & (2.59) \\ \text { PCY } & -0.00001 & 0.000006 & -0.00004 & -0.0001 \\ & (-0.82) & (0.22) & (-1.14) & (-1.31)\end{array}$

black cohorts. One explanation for these areas would tend to have lower values for anomalous results could be the net out- this variable and also lower inmigration migration experienced by the North Central rates.

and Plains States during the sixties, as those In marked contrast to the similarities ex- 


\begin{tabular}{lcccc}
\hline VARIABLE & WHITE MALES & WHITE FEMALES & BLACK MALES & BLACK FEMALES \\
\hline MSR & $\begin{array}{l}-0.022^{*} \\
(-2.25)\end{array}$ & -0.018 & -0.003 & 0.012 \\
& -0.049 & $-1.16)$ & $(-0.17)$ & $(0.46)$ \\
POP & $(-1.23)$ & $(-1.52)$ & -0.077 & -0.124 \\
& -0.000003 & 0.000005 & $0.00002^{*}$ & $(-1.27)$ \\
DIST & $(-0.65)$ & $(0.61)$ & $(2.00)$ & $(2.75)$ \\
$\vec{R}^{2}$ & 0.57 & 0.44 & 0.43 & 0.48 \\
N & 82 & 82 & 74 & 68 \\
d.f. & 67 & 68 & 59 & 54 \\
F & 8.72 & 5.93 & 5.00 & 5.73 \\
\hline
\end{tabular}

\footnotetext{
"The $t$ ratios are in parentheses.

${ }^{n}$ Only those observations in whıch the total number of individuals in a specific race-sex category was at least five were kept in the study This resulted in the deletion of eight observations for black males and fourteen observatıons for black females.

* The coefficient is statistically significant at the $5 \%$ level.

** The coefficient is statistically significant at the $1 \%$ level
}

hibited by area characteristics, personal characteristics show tremendous divergences between the aggregate and disaggregate models. Indeed, it appears that the process of aggregation seriously distorts, or at least masks, some of the factors important to the individual's decision to migrate. Consider the age variable for example.

The disaggregate model reveals that age has a negative impact on mobility and that it is highly significant for all four cohort groups, which is consistent with theoretical expectations. However, the aggregation process seriously distorts the effects of a person's age, as Table I (the aggregate model) shows that age is usually a positive (and significant) determinant of inmigration rates.

Another interesting contrast is provided by the education variable (EDUC). The education of an individual (as opposed to the average educational level of an area, AVED) has a positive influence upon mobility for all cohort groups in Table II except black females. Compare these results to those obtained in Table 1 . The education variable there is significant only for white males.

A similar dichotomy may be noted for the personal unemployment variables (UN5YA and \%UNG). Table II shows that an individual who was unemployed in 1965 (UN5YA) is more likely to have migrated over the 1965-1970 period than an individual who was employed in 1965 regardless of race or sex. This result supports an earlier study conducted by the Bureau of Labor Statistics in 1962-1963 which determined that unemployed men are twice as likely to migrate as employed men [15]. In contrast to this, employment status has no impact on the other cohort groups in Table I.

A lack of significance is also evident in Table I for the military status variable (\%MIL). Once again, however, this variable's counterpart in the disaggregate model 
TABLE II

Detfrminants of Migration by SeX and by Race: Disaggregate Modei ${ }^{a}$

VARIABLE

WHITE MALES

WHITE FEMALES

BLACK MALES

BLACK FEMALES COEFF ICIENTS

\begin{tabular}{|c|c|c|c|c|}
\hline CONSTANT & $\begin{array}{l}-2.048^{* * *} \\
(-2.56)\end{array}$ & $\begin{array}{l}-3.225^{*} \\
(-1.90)\end{array}$ & $\begin{array}{l}-3.104^{*} \\
(-2.24)^{*}\end{array}$ & $\begin{array}{l}-5.766^{* * *} \\
(-2.41)\end{array}$ \\
\hline
\end{tabular}

PERSONAL

CHARACTERISTICS

DMAR

$$
0.096
$$

(1.61)

$-0.003$

$(-0.03)$

$$
\begin{aligned}
& -0.131^{*} \\
& (-1.90)
\end{aligned}
$$

0.035

$0.499^{* *}$

$0.278^{* *}$

$(0.27)$

UN5YA

(7.80)

(2.83)

$0.196 \%$

$0.484^{* * *}$

(2.20)

(4.21)

DM5YA

$$
0.918^{* * *}
$$

(9.31)

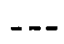

$0.965 * *$

(5.18)

PREVM

$$
0.617^{* *}
$$

$0.459^{* *}$ (14.12)

$$
\text { (5.19) }
$$

$$
\begin{aligned}
& 0.424^{* *} \\
& (6.24)
\end{aligned}
$$

$$
0.363^{* *}
$$

AGE

$$
{ }^{-0.022^{* *}}
$$

$-0.024^{* *}$

$(-7.20)$

$$
-0.028^{* *}
$$

$(-9.07)$

EDUC

$$
\begin{aligned}
& 0.065^{* *} \\
& (9.90)
\end{aligned}
$$$$
0.054^{* *}
$$

$0.045 \%$

0.019

(3.45)

$(4.70)$

(1.07)

AREA

CHARACTERISTICS

\begin{tabular}{lcccc} 
\%UN & $-0.039^{* * *}$ & -0.017 & -0.032 & 0.005 \\
& $(-2.68)$ & $(-0.54)$ & $(-1.19)$ & $(0.10)$ \\
GRW & $0.010^{* *}$ & $0.028^{* * *}$ & 0.002 & 0.003 \\
& $(3.81)$ & $(4.96)$ & $(0.31)$ & $(0.35)$ \\
URB & $0.486^{* *}$ & -0.088 & & 0.164 \\
& $(3.05)$ & $(-0.29)$ & $(1.17)$ & $(0.37)$ \\
TEMP & 0.004 & 0.007 & $-0.015^{* * *}$ & $-0.021^{* *}$ \\
& $(1.44)$ & $(1.09)$ & $(-2.85)$ & $(-2.24)$ \\
AVED & 0.046 & 0.014 & $0.281^{* * *}$ & $0.442^{* * *}$ \\
& $(0.79)$ & $(0.10)$ & $(2.79)$ & $(2.62)$ \\
\hline
\end{tabular}

(DM5YA) has the hypothesized sign and is highly significant for both male cohort groups.

The previous migration variable,
PREVM, indicates that those persons who migrated at least once prior to 1965 were more likely to migrate between 1965 and 1970. The high $t$ ratios and actual values of 


\begin{tabular}{lcccc}
\hline VARIABLE & WHITE MALES & WHITE FEMALES & BLACK MALES & BLACK FEMALES \\
\hline PCY & $-0.0001^{*}$ & $0.0003^{*}$ & -0.0002 & -0.00001 \\
& $(-1.65)$ & $(1.71)$ & $(-1.22)$ & $(-0.03)$ \\
MSR & $-0.092^{*}$ & 0.029 & -0.046 & 0.014 \\
& $(-1.90)$ & $(0.39)$ & $(-0.79)$ & $(0.13)$ \\
POP & $-0.0000003^{* * *}$ & -0.00000002 & -0.018 & 0.003 \\
$\mathrm{R}^{2}$ & $(-2.92)$ & $(-0.87)$ & $(-1.12)$ & $(0.11)$ \\
Pearson $\mathrm{R}^{2}$ & 0.26 & 0.24 & 0.22 & 0.26 \\
$\mathrm{~N}$ & 0.17 & 0.14 & 0.14 & 0.17 \\
d.f. & 8118 & 1816 & 3629 & 1417 \\
Chi $_{\text {Squared }}$ & 8102 & 1801 & 3613 & 1402 \\
\hline
\end{tabular}

\footnotetext{
${ }^{a}$ The $t$ ratios are in parentheses.

"Chi-Squared is computed as $(-20)$ times the natural logarithm of the likelihood ratio The associated degrees of freedom are 14 for both male groups and 13 for both female groups See Tobın [17] or Finney [2] for detals.

* The coefficient is statistically significant at the $5 \%$ level

** The coefficient is statistically signıficant at the $1 \%$ level.
}

the coefficients suggest that this variable plays a very important role in the migration process. Thus, future research should separate those who move for the first time from previous migrants, particularly to gain further insights into the first move.

\section{REASONS FOR DISCREPANCIES BETWEEN MODELS}

There are two reasons why the results differ between the aggregate and disaggregate models. As is well known, the process of aggregation reduces the total amount of variation that remains in any variable, unless all observations in each class are actually at the class mean. In the present case, the variance within each class (i.e., labor market area) in

\footnotetext{
${ }^{7}$ See J. Kmenta $[9$, pp. 322-36] for a complete discussion of the problem
}

the aggregate study is much greater than the variance between the mean values for such variables as age and education. ${ }^{8}$ Indeed, most of the differences in mean values between areas are not significant. Thus, measured significant relationships between age and the inmigration rate, for example, may be highly spurious.

Further, the weights attached to each area in the aggregate model are the same, although some areas are as much as fifty times

\footnotetext{
${ }^{8}$ The results are avalable from the authors Because the other personal characteristics used in the study switch from contınuous to dichotomous variables between the two models, different computational formulas for the variance are required. This difference causes their variances to be less in the disaggregate model. However, If the same computational formula could be employed, the disaggregate model would reveal greater variances for the dummy variables Thus, the authors feel that the variance measures for these variables are non-comparable
} 
as large as others. Even though the dependent variable was normalized to alleviate problems of heteroskedasticity, the question of bias in the resulting estimators remains.

Secondly, the two models differ in exactly whose personal characteristics are being measured. Whereas the aggregate model used average values which referred to the personal characteristics of inmigrants only, the disaggregate model was able to compare and contrast the personal characteristics of migrants vis a vis continuous residents. Our results are highly supportive of the descriptive studies of migration noted in Section II which showed that migration is a selective process favoring the young and the highly educated. Mean values for the personal characteristics show large differences between the two models, and always in the direction one would expect on a priori grounds. For example, the mean age is higher, and mean level of education is lower in the disaggregate study, reflecting the fact that continuous residents tend to be older and less educated.

\section{ELASTICITIES OF DETERMINANTS}

Since the disaggregate model is more consistent than the aggregate model in terms of sign responses and significance, particularly for personal characteristics of individual $\mathrm{mi}$ grants, the disaggregate model was chosen for a more detailed discussion of the determinants of migration.

There are two different methods which can be employed to determine which variables in the dissagregate model are important factors in the migration decision. The standard statistical method is to look at the $t$ ratios associated with the individual coefficients. From this perspective, a person's age, previous migration status, employment status five years ago, and education are always important. The destination area's educational characteristics are also important.

Alternatively, from an economic standpoint, the estimated elasticities show which determinants elicit the greatest response in migration status. Table III was developed for this purpose.

Table III, which displays the elasticities of the determinants, shows that migration is highly responsive to the age and education of the chief income recipient. The propensity to migrate, is, of course, inversely related to an individual's age, but black migration tends to be inhibited more by increasing age than white migration. This result lends credence to Bowles' [1] suggestion that blacks' shorter time horizon reduces their mobility. With respect to the education of a migrant (EDUC), small increases in education increase the likelihood that whites will migrate to a greater degree than is the case for blacks. Nonetheless, all four cohort groups display a relatively elastic response to changes in education.

Previous migration also tends to enhance mobiiity, regardless of race or sex. However, it appears that male migration is more responsive to this variable than female migration.

Finally, black females are much more sensitive to employment status than the other cohort groups.

With respect to labor market characteristics, there is much less consistency. Indeed, blacks (whites) appear to be highly responsive to area characteristics which do not have a significant impact on whites (blacks).

Whites show an elastic response to lower unemployment rates, high levels of employment growth and areas of high urbanization. The results concerning per capita income of an area are contradictory. ${ }^{9}$

Undoubtedly, there is some collinearity between the area characteristics which might

\footnotetext{
${ }^{9}$ The nomınal per capita income variable does not adjust for cost of living differentials between areas. If migrants do not suffer from money illusion, then real per capita income is the more appropriate variable. Unfortunately, cost of living data is not available for all cities, and thus such an adjustment is not possible in this paper. Nonetheless, the cost-of-living differences may affect the significance of the income coefficent We are grateful to an anonymous referee for bringing this to our attention.
} 
TABLE III

Elasticities of the Determinants of Migration by Race and Sex: Disaggregate Modei.

VARIABLE

WHITE MALES

WHITE FEMALES

BLACK MALES

BLACK FEMALES

PERSONAL

CHARACTERISTICS

DMAR

0.75

$-0.01$

$-0.90 *$

0.09

UN5YA

$0.43^{*}$

$0.59 *$

$0.22^{*}$

$1.00 *$

DM5YA

$0.22 *$

$--$

$0.20 *$

PREVM

$2.41 *$

$1.54^{*}$

$1.06 *$

$1.33^{*}$

AGE

$-8.37 \%$

$-8.26^{*}$

$-10.64 *$

$-12.35^{*}$

EDUC

$7.01 \%$

$5.26^{i}$

$4.14^{*}$

1.77

AREA

CHARACTERISTICS

$\begin{array}{lcccr}\text { \%UN } & -4.64^{*} & -1.77 & -3.85 & 0.56 \\ \text { GRW } & 1.96^{*} & 4.98^{*} & 0.33 & 0.59 \\ \text { URB } & 3.29^{*} & -0.52 & 2.00 & 1.02 \\ \text { TEMP } & 1.99 & 3.06 & -8.12 * & -10.37^{*} \\ \text { AVED } & 5.91 & 1.54 & 36.40 * & 52.09 * \\ \text { PCY } & -4.24^{*} & 8.76^{*} & -5.68 & -0.27 \\ \text { MSR } & -0.57^{*} & 0.16 & -0.35 & 9.80 \\ \text { POP } & -0.90^{*} & -0.49 & -0.56 & 0.09\end{array}$

* Based on coefficient which was significant in Table II.

have affected the estimated relationships. This is a common problem in all migration studies. However, the results shown in Table III pose the following question: which variables should be left out? Given the highly diverse results between groups, it is not surprising that preliminary analyses gave no direction concerning which variables to prune. Further, one purpose of the study was to incorporate a full range of labor market and geographical characteristics in a "complete" model of migration. Thus, it was decided to leave all of the area characteristics in the equations.

It is interesting to compare the results of the present study with those of previous efforts. Recall our contention that those studies were biased because at least one dimen- 
sion of the migration decision was excluded from the empirical analysis. Our focus will be Greenwood's 1969 study [7] and the more recent effort by Kalunzny [8]. ${ }^{10}$ Both were selected because they represent polar cases with regard to the use of area and personal characteristics.

Greenwood found that inmigration rates respond inelastically to all of the area characteristics used in this study. In contrast, our analysis shows highly elastic responses to those determinants which are significant (with the exception of the migrant stock rate and population).

The estimated elasticities of the personal characteristics shown in Table III are much more elastic than those reported by Kaluzny. Significantly, the personal education variable is highly elastic in our study, while Kaluzny estimated that education had an inelastic impact on migration.

\section{CONCLUSIONS}

The results of this study show that previous attempts to measure the impact of personal and area characteristics on migration are biased. Previous studies tend to seriously underestimate the elasticities of the various determinants.

A study of the coefficients for the disaggregate model reveals that: i) the personal characteristics of age, education, previous migration, and employment status prior to migration all display patterns consistent with economic theory; ii) these patterns hold regardless of the socio-demographic group; iii) no such pattern is demonstrated for area characteristics; iv) in terms of both the significance of the coefficients and the computed elasticities, personal characteristics play a much more important role in the migration decision than do the characteristics of destination areas; and v) geographical characteristics are of only secondary impor-

\footnotetext{
${ }^{10}$ Such comparisons are certainly limited because of differences in the models and data used. Obviously, we feel that our estimates are more precise.
}

tance, although they are accorded primary importance among professional economists if one judges importance by the amount of space devoted to them in leading academic journals.

The final objective of this paper was to discover the sensitivity of the determinants of migration to different levels of aggregation. Two models, an aggregate and disaggregate version based on the same data, were estimated and compared. A comparison revealed that the process of aggregation camouflages some of the personal characteristics which are important determinants of an individual's decision to migrate while it had only a marginal effect on the labor market characteristics of an area.

In his excellent survey article on migration research, Michael Greenwood reconciles the conflicting results obtained by several investigators concerning the impact of migration on earnings by concluding:

"Conclusions drawn on the basis of information on the population as a whole may well not apply to various populations or labor force subgroups (e.g., to blacks)" [5, p. 401].

To which the present authors would add: nor should conclusions concerning the personal characteristics of migrants be drawn on the basis of aggregate data.

\section{REFERENCES}

1. Bowles, S., "Migration as Investment: Empirical Tests of the Human Investment Approach to Geographical Mobility." Review of Economics and Siatisucs, November, 1970, 356-62.

2. Finney, D J., Probit Analysis, 3rd ed. Cambridge, England: Cambridge University Press, 1971.

3 Gallaway, L.E., "Age and Labor Mobility Patterns." Southern Economic Journal, October, $1969,171-80$.

4.— R.F. Gilbert, and P.E Smith, "The Economics of Labor Mobility: An Empirical A nalysis." Western Economic Journal, June, 1967, $211-23$.

5. Greenwood, M.J., "Research on Internal Migration in the United States: A Survey." The Journal of Economic Literature. June, 1975, 397-433.

6. Empirical Analysis: Comment." Western Economic Journal, June, 1968, 243-44.

7. "An Analysis of the Determınants of Geog- 
raphic Labor Mobılity in the United States." Review of Economics and Statistics, May, 1969. 189-94.

8. Kaluzny, R.L., "Determinants of Household $\mathrm{M}_{1-}$ gration: A Comparative Study by Race and Poverty Level." Review of Economics and Statistıcs, August, 1975, 269-74.

9. Kmenta, J., Elements of Econometrics. New York. MacMillan Publishıng Co., Inc., 1971.

10. Ladinsky, J., "The Geographical Mobility of Professional and Technical Manpower." Journal of Human Resources. Fall, 1967, 475-94.

11. Lowry, I.S, Migration and Metropolitan Growth: Two Analytical Models San Francisco Chandler Publishing Company, 1966.

12. Persky, J.J. and J.F. Kain, "Migration, Employment and Race in the Deep South." Southern Economic Journal, January, 1970, 268-76.

13. Raimon, R.L., "Interstate Migration and Wage Theory "Review' of Economics and Statistics, November, 1962, 428-38.

14. Rogers, A., "A Regression Analysis of Interregional Migration in California." Review of Economics and Statistics, May, 1967, 262-67.

15. Saben, S, "Geographical Mobility and Employ- ment Status: March 1962-March 1963." Monthly. Labor Revlew. August, 1964, 873-81.

16. Suval, F.M. and C.H. Hamilton, "Some New Evidence on Educational Selectivity in Migration to and from the South." Social Forces, May, 1965, 536-47.

17. Tobin, J. "Estimation of Relationships for Limited Dependent Variables." Econometrica. January, $1958,24-36$

18. Wadyckı, W.J., "Alternatıve Opportunities and Interstate Migration: Some Additional Results." Review of Economics and Statlstics, May, 1974, 254-57.

19. Weiss, L. and J.G. Williamson, "Black Educatıon, Earnings, and Interregional Migration: Some New Evidence." American Economic Review, June, 1972, 372-83.

20. Wertheimer, R.F., The Monetary Rewards of Migratlon Within the US Washington, D.C.: The Urban Institute, 1970.

21. U S. Department of Commerce, Public Use Samples of Basic Records from the 1970 Census Descripuon and Technical Documentation Washington, D.C.. U. S. Government Printıng Office, 1972. 